\title{
EL CAPITAL FÍSICO, HUMANO Y SOCIAL; Y LA RESPONSABILIDAD DEL CONTADOR PÚBLICO CON LA POBREZA
}

\author{
PHYSICAL CAPITAL, HUMAN AND SOCIAL AND RESPONSIBILITY \\ PUBLIC ACCOUNTANT WITH POVERTY
}

\section{Zelma Wong TorRes*}

Docente Principal de la Facultad de Ciencias Contables, UNMSM

\section{Luisa Elena Salcedo Guzmán **}

Docente Asociada de la Facultad de Ciencias Contables, UNMSM

[Recepción: Febrero de 2011/ Conformidad: Abril de 2011]

\section{RESUMEN}

El presente artìculo es producto de la investigación llevada a cabo en el 2010, intitulada, Capital físico, humano y social; y la responsabilidad social del Contador Público con la Pobreza. En este artículo se busca manifestar el interes por los mecanismos de solución para alcanzar la equidad y lograr una estrategia de desarrollo. En esa perspectiva, el artìculo ha insistido en que la política social debe tener la capacidad de influir en los determinantes estructurales a traves de los cuales se reproducen la pobreza y la desigualdad, la mala distribución de las oportunidades educativas y ocupacionales, la pronunciada desigualdad en la distribución de la riqueza, la aun elevada dependencia demográfica, y las dimensiones etnicas y de genero que las acompañan. A partir de este análisis, hemos destacado tres factores como es el capital humano, social y fisico; además de destacar el papel de responsabilidad social de la profesión Contable.

Palabras Claves: Contabilidad, capital social, capital físico, capital humano, responsabilidad social del contador, Pobreza Extrema.

\begin{abstract}
This article is the result of research carried out in 2010, entitled, physical capital, human and social, and social responsibility of the Certified Public Accountant with Poverty. This article seeks to demonstrate the interest in settlement mechanisms to achieve equity and achieve a development strategy. In this perspective, the article insisted that social policy should be able to influence the structural determinants through which reproduce poverty and inequality, maldistribution of educational and occupational opportunities, the sharp inequality the distribution of wealth, even high demographic dependency, and ethnic and gender dimensions that accompany them. From this analysis, we highlighted three factors as human capital, social and physical, while highlighting the role of social responsibility of the accounting profession.
\end{abstract}

Key words: Accounting, social capital, physical capital, human capital, social responsibility, the accountant, Extreme Poverty.

\footnotetext{
* Magister en Ciencias Contables, UNMSM; Contadora Pública Colegiada Certificada. Docente Investigadora de la Facultad de Ciencias Contables - UNMSM.

Email: zwongt@hotmail.com

** Egresada de Postgrado- Doctorando, UNMSM; Contadora Publica Colegiada Certificada; . Docente Investigadora de la Facultad de Ciencias Contables - UNMSM.

Email: luisalcedog@yahoo.es
} 


\section{INTRODUCCION}

Todos tenemos un concepto muy claro sobre lo que es pobreza y lo que significa ser pobre en nuestro país. Siendo éstos individuos o familias que se ubican en una determinada dimensión social, generalmente monetaria, pero no solo ellos son pobres, sino también los socialmente excluidos ya sea por etnia, género, edad, incapacidad física, entre otros.

En la primera parte de este artículo enfocamos la pobreza y la exclusión social, presentando a los contadores que desarrollan su actividad como educadores y si las enseñanzas que imparten están enmarcadas en una calidad espiritual y moral elevada que garantice el desarrollo económico y humano, del profesional Contador Público, la empresa y el Estado.

En la segunda parte alcanzamos a modo general, algunos conceptos del capital físico, humano y social, también una apreciación crítica del por qué los ricos se hacen cada vez más ricos con la exportación de productos elaborados en las empresas, mientras que los países poco desarrollados sólo venden su materia prima para poder subsistir, sufriendo las variaciones en los precios.

Finalmente en la tercera parte se ha investigado cuál es la contribución del contador y su responsabilidad social en el crecimiento sostenido de la economía nacional y como su devenir profesional influye en el quehacer del país.

\section{SITUACIÓN DE POBREZA EN EL PERÚ}

En la actualidad se cita un nuevo concepto de pobreza, definiéndola como: la privación de libertades sustantivas de los individuos. El individuo en situación de pobreza está obligado a vivir una vida que no valora, obligado a sobrevivir y subsistir. También se señala la pobreza humana, como la privación de las cosas valiosas que una persona puede hacer o ser.

La pobreza es un nivel inaceptable de desarrollo humano, la que podemos dividir en 5 capacidades:

1 Capacidad libre de hambre

2 Capacidad libre de enfermedades

3 Capacidad libre de analfabetismo

4 Capacidad de acceder a los servicios básicos.

5 Capacidad de obtener empleo.

Es importante conceptualizar la pobreza para entender sus diferentes causas, su carácter dinámico, reconocer la pobreza como una situación potencial, reconocer desde la inseguridad ciudadana, distinguir las causas y efectos de la pobreza, reconocer su heterogeneidad y romper la logia de unidireccionalidad.

\section{DIVERSOS ENFOQUES Y TEORÌAS}

No se tiene una teoría económica sobre la pobreza, debido a que los científicos sociales no han trabajado al respecto.

La microeconomía no tiene el estudio del comportamiento de los consumidores o familias en condiciones de pobreza o pobreza extrema. La macroeconomía estudia el nivel de empleo y desempleo pero no a nivel de pobreza y pobreza extrema. Tampoco se estudia la desigualdad extrema en la distribución de los ingresos frente a la gran concentración de la riqueza.

La teoría del desarrollo se dedica poco al estudio de la pobreza. No hay teorías ni explicaciones de las causas de la pobreza.

Existen muchos enfoques monetarios y participativos. El primero es un enfoque descriptivo, se centra en la operatividad de la pobreza en lo monetario; es decir, aquellos que 
obtienen el dinero por debajo de la línea de ingresos; en tanto que el segundo enfoque se refiere a conocer o acercarse a la pobreza.

Un enfoque teórico de reconocimiento de la pobreza como un fenómeno multidimensional, es construir un índice agregado para definir su estado o evolución. Sólo ponemos etiquetas a fenómenos complejos, sin la correspondiente explicación del caso, de la economía informal o la marginalidad urbana; aquí apreciamos los enfoques para identificar a los informales, a los marginados, a los excluidos o pobres.

Uno de los ejes de la pobreza es precisamente la definición de análisis, muchos asumen que los pobres son individuos o familias que se ubican generalmente en la parte monetaria. ¿Cuáles de los mencionados tienen estos atributos o no para dejar de ser pobres? Aquí no se busca explicar la pobreza, sino, la focalización geográfica, para formular políticas que reduzcan la pobreza en esas zonas.

Debemos ubicarnos en la teoría estructural de la pobreza, en que los pobres conforman grupos sociales, cuya existencia es el resultado de la composición de los estratos sociales derivados de la estructura económica y social de una sociedad.

\section{ACTIVOS DE LOS POBRES TIENEN ACTIVOS LOS POBRES?... DE QUÉ ACTIVOS HABLAMOS?}

Muchos piensan que la población pobre no podrá crecer por falta de capital físico y capital humano. Se está demostrando que el pobre se está organizando y logrando lo que los políticos no han podido. Estos grupos de organizaciones están buscando financiamiento para poder explotar su tierra; sin embargo, es lamentable que el gobierno peruano, en base a triquiñuelas, esté vendiendo estos activos; o sea, la tierra de esta gente po- bre, bajo el argumento de que no le ve mayor capacidad para desarrollarse; grave error del gobierno, pues no ha realizado un estudio de las características de estos grupos.

Actualmente el crecimiento está concentrado en pocos sectores de la economía, con poco o ningún efecto sobre los más pobres. La tierra es un capital propio, el acceso a los bienes de capital público y capital humano, se halla entre los tipos de producción más rentables.

La combinación adecuada de educación, servicios públicos, acceso al crédito y reforma agraria, debe tratar que los grupos de pobreza salgan de ese estatus logrando ser más productivos, aumentando sus ingresos.

\section{EL ENFOQUE DE LA POBREZA EN EL PERÚ}

El crecimiento económico es el primer factor clave para reducir la pobreza, debiendo efectuarse una redistribución de los activos físicos y el capital humano. El segundo determinante, clave para la reducción de la pobreza está en la distribución de los activos e inversión agregada, así como, los mecanismos políticos y sociales para un mayor acceso de los pobres a los activos que son claves para el aumento de la productividad y los ingresos; todo esto depende de la participación de los pobres en el proceso de crecimiento.

La desigualdad es una restricción al crecimiento, la inadecuada distribución de activos afecta al crecimiento la pobreza y la desigualdad. La desigualdad en el crecimiento se debe a las diferencias en el acceso de la población a los activos productivos. La desigual distribución del capital humano y otros activos productivos representan las restricciones estructurales que limitan el crecimiento de América Latina, esto explica el pobre desempeño del Perú para reducir la pobreza. 
La problemática de la posesión y acceso a activos por parte de los hogares pobres del Perú, surge de los activos privados y públicos y las organizaciones, que son los determinantes de los gastos e ingresos de las familias, es dato crucial para determinar que la familia logre salir de la pobreza.

En el caso de la educación, es probable que la reducción del presupuesto y la dispersión de dicho activo haga que la transformación educativa sea uno de los indicadores de pobreza, variables que explican los cambios identificados de la pobreza y distribución de ingresos.

Los resultados en el sector urbano es que a mayor posesión de los activos, menor será la probabilidad de ser pobre.

En el sector rural, las variables relacionadas a capital público y organizacional están relacionadas a la falta de energía eléctrica, agua y desagüe, no así a la tenencia de la tierra.

Según un trabajo de Francisco Verdera V. menciona que Habich 1989 dije" de las políticas de ajuste y la provisión de necesidades básicas, más en concreto se promovió el acceso de ciertos grupos poblacionales a bienes y servicios básicos". Habich, propone analizar los procesos de crecimiento y cambio mediante los cuales se expanden las capacidades de las personas y se basa en el enfoque de $S^{1}{ }^{1}$, distinguiéndose entre tres acciones: el bien, la característica del bien y el desempeño o funcionamiento que la persona puede alcanzar, provienen de la evaluación de sus opciones de desempeño. Si se obtiene una habilidad para desempeñarse, se alcanza un nivel de calidad de vida.

El enfoque de capacidad permite estudiar a la pobreza, pero, se debe ver que capacida- des esenciales deben considerarse y cuál es el índice de esas capacidades básicas.

En el Perú las familias de asalariados y familias agrícolas se encuentran aisladas por el mercado de bienes y mercado de trabajo de la capital, siendo ambos del mismo estrato se beneficia a unos y se perjudica a otros. En los independientes si hay igualdad en la propiedad de los recursos y el capital.

El enfoque de Sen ha tenido gran influencia a medida que se ha implementado a través del índice de desarrollo humano. Una evaluación del enfoque de posesión de recursos, uso de capacidades y ejercicio de derechos, pasa por verificarse la explicación de la pobreza y las desigualdades, generalmente el enfoque recae sobre individualismos metodológicos, dejando de lado la estructura social, la especificidad histórica y social, propios del análisis estructuralista.

Para llegar a la operacionalización para su medición surgen numerosas opciones metodológicas, aunque la decisiones son muchas veces arbitrarias, la elecciones son más visibles y por tanto, más fáciles de evaluar que el enfoque monetario.

\section{Cuadro No 1}

\begin{tabular}{ll}
\hline ESTRATEGIAS & \multicolumn{1}{c}{ MEDIDAS ASOCIADAS } \\
\hline Oportunidad & $\begin{array}{l}\text { Crecimiento económico, } \\
\text { creando oportunidades de } \\
\text { empleo, créditos, electricidad, } \\
\text { escuelas, abastecimiento de } \\
\text { agua potable, saneamiento } \\
\text { Medidas públicas que respon- } \\
\text { dan a las necesidades de los } \\
\text { pobres. } \\
\text { Gestión de soluciones. } \\
\text { Seguridad }\end{array} \quad \begin{array}{l}\text { Reducción de la inseguridad } \\
\text { por acción gubernamental. }\end{array}$ \\
\hline Fuente: INEI-ENAHO-2004-2009
\end{tabular}

1 Amartya Kumar Sen, economista Bengalí-India. Premio Nobel 1998. 
Cuadro No 2. Importancia de las dimensiones de las políticas públicas

\begin{tabular}{|c|c|c|}
\hline DIMENSIONES & POLÍTICA SOCIAL & POLÍTICA EMERGENTE \\
\hline Objetivos & Combatir la pobreza & $\begin{array}{l}\text { Exclusión social } \\
\text { Equidad Social }\end{array}$ \\
\hline Alcance & Fiscalizar pobreza & $\begin{array}{l}\text { Cobertura universal } \\
\text { Integración económica social } \\
\text { Acciones selectivas y focalizadas. }\end{array}$ \\
\hline Destino & Grupos en situación de pobreza & Grupos en situación de pobreza y exclusión social \\
\hline Estado & $\begin{array}{l}\text { Responsable de la planificación, fi- } \\
\text { nanciación y ejecución de progra- } \\
\text { mas sociales. }\end{array}$ & $\begin{array}{l}\text { Garante de los derechos fundamentales. del hom- } \\
\text { bre } \\
\text { Bienestar e integración social. }\end{array}$ \\
\hline Mercado & $\begin{array}{l}\text { Presencia del sector privado como } \\
\text { prestadores de servicio sociales. } \\
\text { Despolitización. }\end{array}$ & $\begin{array}{l}\text { Efectos del mercado en la actividad privada. } \\
\text { Eficiencia y transparencia en el ámbito social. }\end{array}$ \\
\hline Financiación & $\begin{array}{l}\text { Gasto social Estado } \\
\text { Gasto social Privado } \\
\text { Eficiencia y capital humano }\end{array}$ & $\begin{array}{l}\text { Factibilidad económica. } \\
\text { Equidad social. } \\
\text { Equidad de gasto. }\end{array}$ \\
\hline
\end{tabular}

Fuente: INEI-ENAHO-2004-2009

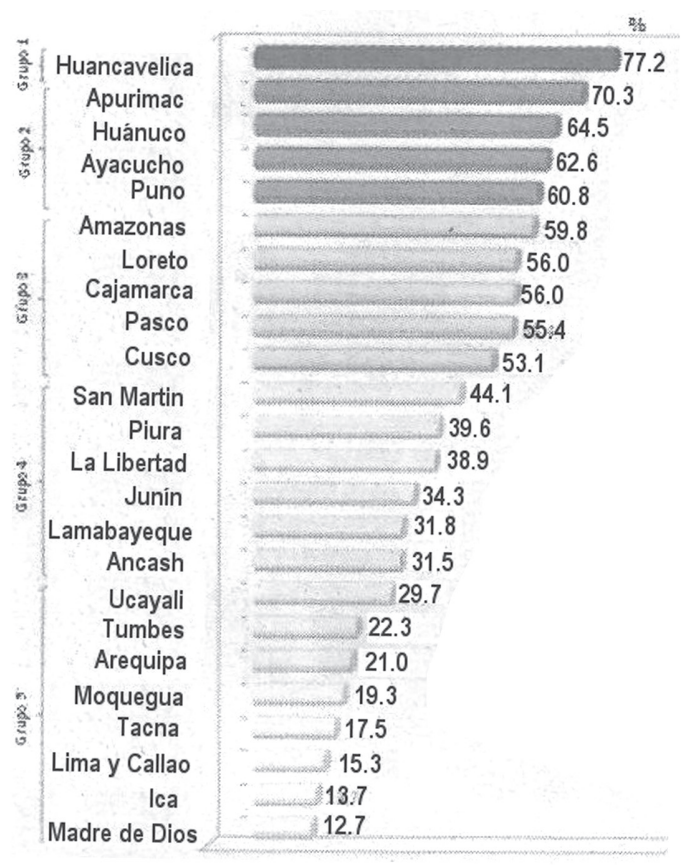

Grafico No 1. PERÚ: Agrupación de Departamentos Índice de pobreza - 2009

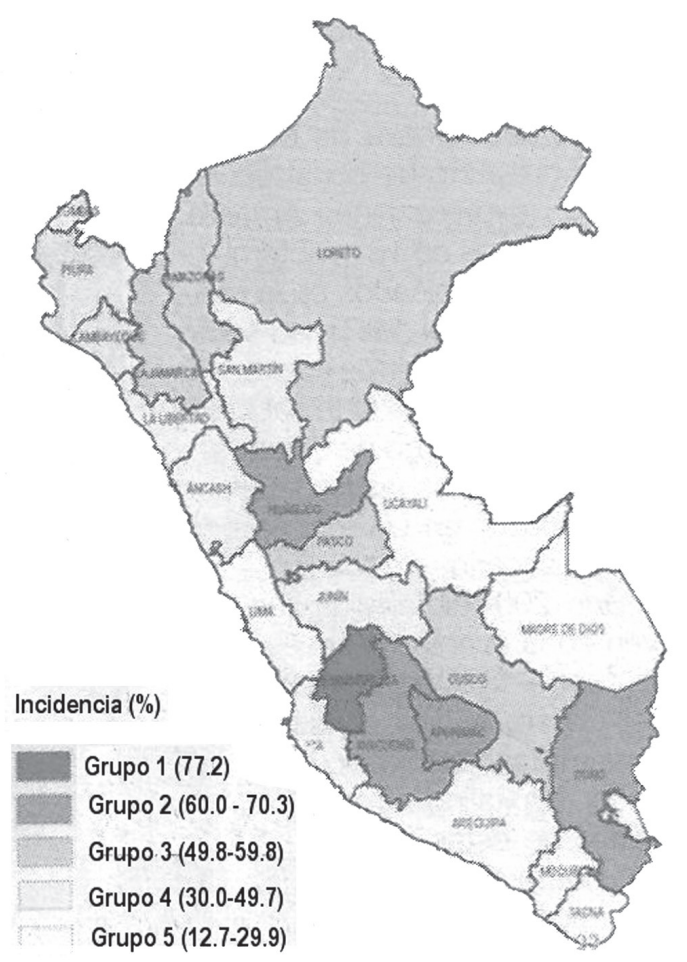

Fuente: INEI-ENAHO 2004-2009- Diario. Diario La Primera 12-09-10 
En una vista general de nuestro país podemos observar que entre las regiones más pobres, se encuentra el Departamento de Apurímac, con el $70.3 \%$ de pobreza, y curiosamente, es el departamento que más lotes tiene concesionado a grandes empresas de hidrocarburos.

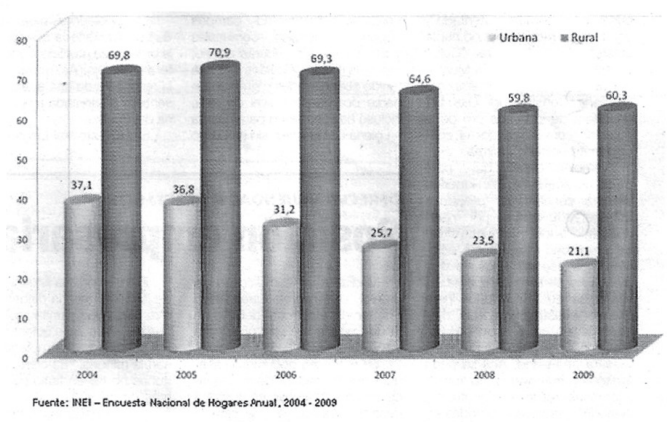

Fuente: Diario La Primera 12-09-10

Grafico No 2. PERÚ: Incidencia de la Pobreza total por Área de Residencia 2004-2009 (Porcentaje)

En términos generales, la pobreza ha disminuido de $48.6 \%$ en el 2004 a $34.8 \%$ en el 2009 tanto el área rural, como en la urbana. Como era de esperarse el índice de pobreza en el área rural siempre es mayor, debido a muchos factores, entre los principales la falta de educación y la exclusión social.

\section{ELSISTEMAS DE PROTECCIÓN SOCIAL}

El sistema de protección social, es un derecho fundamental de las personas para acceder a programas efectivos que disminuyan el riesgo económico y social.

La normatividad a favor de los pobres mejorará su bienestar. Se debe reforzar la capacidad de los sectores más pobres para enfrentar sus riesgos. Se debe identificar los grupos más afectados cubriéndolos con programas y políticas coherentes y evaluar su eficiencia.

Estos sistemas deben caracterizarse por:
- Los esfuerzos deben estar dirigidos a integrar la familia.

- Las políticas deben ser coherentes y positivas tanto a nivel privado como público.

- Las causas de la pobreza, control y supervisar de los resultados de la protección Social integral.

- Las perspectivas de género en los planes y programas de protección social.

- La protección, solidaridad é inversión en la formación de capital humano.

- Las causas de la pobreza y oportunidad de adoptar actividades de riesgo y rentabilidad.

\section{MANEJO SOCIAL DEL RIESGO}

Permite el mejor diseño de los programas de protección social como estrategia de reducción de la pobreza. Con la intervención pública de personas hogares y comunidades para mejorar el manejo de riesgo.

ElEstado debe intervenir de manera integral con familias en extrema pobreza. Debe crear sistemas de protección social integral para las familias en condición de extrema pobreza. La solidaridad es una forma de abordar la extrema pobreza. Integrar las familias en redes de servicios y programas dirigido a ellas, para superar las condiciones de extrema pobreza.

Cuadro No 4. Evolución Porcentual de Pobreza. Perú 2004-2009

\begin{tabular}{llllc}
\hline Año & $\begin{array}{l}\text { Población } \\
(\text { Miles })\end{array}$ & $\begin{array}{l}\% \\
\text { breza }\end{array}$ & $\begin{array}{l}\text { Pobres } \\
\text { (Miles) }\end{array}$ & $\begin{array}{c}\text { Cambio } \\
\text { (Miles) }\end{array}$ \\
\hline 2004 & 26,896 & $48.6 \%$ & 13,071 & \\
2005 & 27,219 & $48.7 \%$ & 13,256 & 185 \\
2006 & 27,546 & $44.5 \%$ & 12,257 & $(999)$ \\
2007 & 28,220 & $39.3 \%$ & 11,090 & $(1167)$ \\
$2008^{*}$ & 28,807 & $36.2 \%$ & 10,428 & $(662)$ \\
$2009^{*}$ & 29,132 & $34.8 \%$ & 10,138 & $(290)$ \\
\hline (*) Población Estimada según INEI $^{\text {Fuente: } \text { www.inei.gob.pe }}$
\end{tabular}


$\mathrm{Al}$ año 2009, en Perú existían aproximadamente 10,138000 personas afectadas por la pobreza, lo que constituye el $34.8 \%$ de la población total del país.

Cuadro No 5. Ranking de Pobreza América Latina 2008

\begin{tabular}{lc}
\hline \multicolumn{1}{c}{ País } & $\mathbf{2 0 0 8} \%$ \\
\hline Honduras & 63.1 \\
Nicaragua & 54.4 \\
Paraguay & 50.2 \\
Bolivia & 47.2 \\
Guatemala & 46.7 \\
Colombia & 40.6 \\
El Salvador & 40.4 \\
República Dominicana & 40.1 \\
Perú & 36.2 \\
Ecuador & 33.1 \\
México & 27.9 \\
Venezuela & 23.6 \\
Panamá & 21.5 \\
Brasil & 19.9 \\
Costa Rica & 14.8 \\
Argentina & 14.7 \\
\hline
\end{tabular}

Fuente: INEI: www.inei.gob.pe. CEPAL: www.cepal.es
Según estadísticas proporcionadas por la Comisión Económica para América Latina (CEPAL) y datos tomados del INEI al 2008, Perú se ubicaba en el $9^{\circ}$ lugar, que podríamos catalogar como, un lugar intermedio, entre los países de América Latina, con el 36.2\% de su población en situación de pobreza.

Se tiene tres grandes enfoques para medir la pobreza, éstos son: la pobreza absoluta, pobreza relativa y la exclusión social.

Si hablamos de pobreza, no podemos dejar de mencionar el caso de Haití, país que en enero del 2010 sufrió un terremoto, que desbastó todo el país, agudizándose el problema de miseria. Es el país más pobre del hemisferio occidental. Este terremoto dejó 250,000 muertos y 1.5 millones de damnificados que están constantemente amenazados por los huracanes, no contando con albergues seguros según estadísticas de la CEPAL.

Debido a esta catástrofe se realizó la Cumbre Mundial sobre el futuro de Haití. Cumbre en la que los países participantes se comprometieron a aportar en cada uno de los aspectos del plan de acción para la recuperación y el desarrollo de Haití: ejes de

Cuadro No 6. Políticas Públicas contra la Pobreza

\begin{tabular}{|c|c|c|}
\hline Año & Estado & Políticas Públicas dirigidas a la pobreza \\
\hline $1900-1930$ & Protector & Programa de Protección Social. \\
\hline 1932-1955 & Benefactor & $\begin{array}{l}\text { Beneficios Sociales. } \\
\text { Amplia cobertura. } \\
\text { Vivienda, educación y asistencia. }\end{array}$ \\
\hline 1964-1973 & Redistribuidor & $\begin{array}{l}\text { Fortaleza. } \\
\text { Seguridad social y salud. } \\
\text { Medida de redistribución de la tierra. }\end{array}$ \\
\hline 1974-1989 & Ausente & $\begin{array}{l}\text { Menor protagonismo del Estado. } \\
\text { Privatización de la función social. } \\
\text { Acción hacia grupos prioritarios. }\end{array}$ \\
\hline 1990-hoy & Subsidiario & $\begin{array}{l}\text { Incorpora concepto de equidad, promoción } \\
\text { social y autogestión. }\end{array}$ \\
\hline
\end{tabular}

Fuente: INEI-RNSHO-2004-2009 
ordenamiento y desarrollo territorial, desarrollo económico, desarrollo institucional y desarrollo social, y recuperación cultural.

Se acordó darles 11,000 millones de dólares americanos:

- Venezuela le ha condonado la deuda a través del Alba (Alianza Bolivariana) para los pueblos de nuestra América, y la deuda que Haití tenía con Petrocaribe de 395 millones de dólares.

- Estados Unidos se comprometió a donar 47,000 viviendas provisionales.

- La Comunidad Internacional 125,000 viviendas para apaciguar la emergencia habitacional.

- La Unión Europea se comprometió a entregar 460 millones de dólares americanos.

- Francia 400 millones de dólares americanos.

- Australia 50 millones de dólares americanos.

- Canadá 280 millones de dólares americanos.

- Colombia 100 millones de dólares americanos.

- Brasil 55 millones de dólares americanos.

- El Banco Interamericano de Desarrollo (BID) 2,200 millones de dólares americanos.

- Banco mundial 150 millones de dólares americanos.

Con estos aportes el país puede ser autosostenible. Los niveles de miseria de Haití, regresaron al 2001, que era $71 \%$ de pobreza moderada y $50 \%$ de pobreza extrema, según estadística de la CEPAL.

Oscar Ugarteche, nacido en 1949, investigador titular definitivo en el instituto de investigaciones económicas de la Universidad Nacional Autónoma de México (UNAM) Coordinador del Observatorio Económico Latinoamericano (OBELA) y presidente de la Agencia Latinoamericana de Información (ALAI) y otras organizaciones en una reciente visita a Argentina ofreció una conferencia en la sede de la Facultad de Ciencias Económicas (FCE) de la Universidad de Buenos Aires (UBA), donde remarcó la necesidad de avanzar en la integración regional, apuntando a los bienes manufacturados regionales en lugar de las materias primas extra regionales, en un mundo de cambio tecnológico en el que se utiliza el petróleo decrecientemente.

Apuntar a la utilización de monedas locales dejando de lado el dólar estadounidense como parámetro de referencia, en medio de un mercado de retroceso del comercio internacional, por el impacto recesivo que ahora tiene epicentro en Europa, con la explosión hasta el momento de los abultados déficits fiscales de España, Grecia e Irlanda, también presentes en otras economías, tras de puntualizar el paso por el ajuste con sus recortes salariales y de consumo.

La crisis bancaria será la gran crisis más profunda por la que atraviesa el sistema capitalista mundial de la llamada globalización, va desde lo ambiental hasta lo religioso, pasando por lo económico y lo ideológico. Una pregunta que debemos hacernos es ¿por qué hogares pobres que no lo eran han pasado a serlo?

El tamaño de la familia es determinante para explicar por qué ciertos hogares se mantienen en estado de pobreza.

Aquí habría que ver las estrategias de supervivencia con la trayectoria de ascenso social, estrategias de movilidad e integración social que es el capital social de los hogares

Deben haber planes de largo plazo que aseguren la inversión de activos de capital humano para aprovechar las oportunidades que ofrecen las sociedades modernas, alcanzar los niveles de bienestar y la utilización de recursos, que permitan la inclusión en el 
mundo moderno de los nuevos patrones de movilidad e integración social que reflejen el cambio de las estructuras y de oportunidades que ofrece el mercado.

¿Cómo responde mi hogar cuando los ingresos declinan? ¿El empleo es escaso? ¿Los gastos fijos son los mismos? Aquí nos preguntamos como hace el pobre para enfrentar situaciones críticas, y cuáles son las oportunidades que le ofrece el mercado, el Estado, la sociedad, aquí surgen una serie de atributos que posee la familia, ellos identifican las condiciones generadas y el refuerzo a las capacidades propias del hogar, que tienen para el mejoramiento sostenido y progresivo de uno de su miembros, aquí se aprecia la infraestructura, la vivienda y la capacidad de supervivencia del hogar, en este aspecto se analiza en forma más directa los activos que posee el hogar, aquí se identifica la lógica, la interdependencia y reproducción del núcleo familiar, aquí se cumple aquello de amarás a tu prójimo como a ti mismo, y en el Perú podemos decir que en muchas partes se cumple esto.

Para logar la meta del hogar como tal se rompe barreras que impidan lograr parte o algo de los objetivos planteados para integrar a uno de sus miembros en la sociedad.

Se puede salir de la pobreza variando nuestra tenencia de activos, siempre que se logre hacer algo o se tenga un empleo como fuente de ingreso, es una de las salidas de la pobreza y si no calculamos bien regresar a ella. Es necesario aquí acceder a las oportunidades que nos ofrezca el mercado, que promueva mas allá de las oportunidades, debiendo estructurarse la parte económica que determina la demanda de trabajo de bienes y servicios para actividades productivas de las familias.

Salir de la pobreza dependerá de la configuración de los activos según su potencial o efectividad, frente a una lógica de superviven- cia o un ascenso social, también hay que tener en cuenta la calidad, ubicación de los recursos, del hogar y el nivel de productividad, debiendo analizarse la distribución del ingreso familiar entre los pobres del hogar sin ningún egoísmo, y en un corto o mediano plazo estaríamos frente a otro análisis del hogar.

La gran desigualdad que hay en el Perú entre ricos y pobres está vinculada a la desigualdad en el reparto de los recursos que hace que cada vez que el rico sea más rico y el pobre cada vez más pobre; una falta de estructura productiva sectorial y geográfica no permite que el pobre tenga una movilidad suficiente para distribuirse entre regiones, con el fin de generar fuentes de ingresos. Salir de la pobreza depende de las características de los individuos y las familias.

\section{TRATADOS DE LIBRE COMERCIO: OPORTUNIDAD PARA PERÚ:}

El libre comercio impulsa el crecimiento y reduce la pobreza. Perú tiene en frente una oportunidad enorme con la firma de los Tratados de Libre Comercio (TLC).

En el caso del TLC con Estados Unidos, este tratado representa un potencial incremento del empleo en ambos países ya que la producción tendería a dinamizarse, ofrece ventajas políticas y diplomáticas positivas, ofrece la oportunidad a las empresas de EE.UU. de venir al Perú fortalecer la relación.

EE.UU. ya está saliendo de la crisis, ahora ha crecido a un ritmo de $3 \%$ en un año y medio. Se debe crear nuevos nichos, buscar nuevos mercados para tener nuevas alternativas cabe citar: Arabia Saudita invertirá US\$ 500 mil millones en los próximos 10 años y demandará materias primas que produce el Perú. EE.UU. compra productos al Perú con valor agregado, esto hay que tenerlo en cuenta al momento de pensar en exportar. 
Respecto al TLC con China, hay que ser conscientes de la dimensión de la economía China, del 4\% del total de la producción a nivel mundial en 1990 paso al 13\% en el 2009 . El fondo monetario internacional prevé una tasa de crecimiento en China del 10\% y una proyección del $9.7 \%$ de crecimiento para el 2011, apuntalándose como uno de los principales motores de la economía mundial.

En el 2010 entró en vigencia el Tratado de Libre Comercio con China. Este país, se ha consolidado como nuestro segundo socio comercial, constituyéndose en un mercado potencial de 1,300 millones de consumidores por lo que se prevé pase a ser nuestro principal socio comercial en los próximos años.

Cuáles son los principales productos que componen la balanza comercial con China, y que está detrás de los permanentes superávits comerciales con ese país?: Los minerales, especialmente el cobre y los pesqueros, representan el $70 \%$ y $10 \%$ del total de las exportaciones a China, ambos rubros primario-extractivos suman el $80 \%$ de la totalidad de nuestras exportaciones a China, estos son los principales recurrentes del superávit comercial con China, el resto de sectores de la balanza comercial ha sido deficitaria. Exportamos productos manufacturados a China que le da un creciente valor agregado al sector textil siendo esta área la más sensible para nuestra economía nacional.

Nuestra relación comercial con China se basa en exportar materia prima e importar productos manufacturados. El protagonismo de las agro-exportaciones en la economía nacional, que con el TLC con China recibirán un mayor impulso exportador, hay que tener en cuenta que la actividad agrícola es una de las más intensivas en mano de obra y está focalizada principalmente en las provincias del país. Los productos agrarios con fines de exportación, generan entre dos y tres veces más demanda de mano de obra que los cultivos tradicionales, debido al mayor nivel de especialización de estos productos que conlleva a una cadena productiva más amplia que incluye servicios de acopio y selección de producciones, productos fitosanitarios y equipos de riego tecnificado. Perú posee excelentes condiciones geográficas y climáticas para la producción agro-exportadora y asimismo se ha consolidado con una fuerte demanda mundial por el consumo de alimentos.

El sector agro-exportador constituye una oportunidad para iniciar la reconversión del proceso de integración comercial de nuestra economía, la experiencia de Corea del Sur, que se creía debía especializarse en la exportación de arroz, sin embargo, su gobierno optó por centrarse en la adquisición de tecnología y especialización profesional.

El proceso de integración comercial sería más factible en el sector primario exportador o redefinir nuestra relación con la globalización.

Con el TLC Europeo, se aprecia un notable desarrollo de América Latina consolidando una política de paz menos violenta que la de Europa y con un creciente comercio vía tratado de libre comercio, expresándose en un intercambio fluido, un comercio justo y relaciones de igualdad y equidad.

La declaración Schuman de mayo de 1950 que crea la UE decía, "La organización proyectada al contrario que un cartel internacional tendente a la distribución y a la explotación de los mercados mediante prácticas restrictivas y el mantenimiento de grandes beneficios garantizará la fusión de los mercados y la expansión de la producción. Los principios y compromisos esenciales anteriormente expuestos serán objeto de un tratado firmado entre los estados"

El exhaustivo trabajo de los especialistas Alan Fairlie Reinoso ${ }^{2}$ y Sandra Queija de la 
Sotta sobre "Una nueva perspectiva andina y las relaciones con Europa", desde Junio 2007 se lanzaron desde la cumbre de Tarija las negociaciones para un acuerdo de asociación entre la Unión Europea (UE) y la Comunidad Andina de Naciones (CAN) con componente comercial de cooperación de consulta política.

Finalmentela UE aceptó negociar solamente con Colombia y Perú, pero, por separado.

Los países andinos que tienen una participación mayoritaria en el intercambio comercial entre los dos bloques, son Colombia y Perú.

La CAN exporta principalmente materias primas o productos con bajo valor agregado mientras que la UE exporta productos con alto valor agregado.

En la presente década han emergido algunos productos que significan un cambio de patrón exportador. La complementariedad entre la estructura exportadora de la CAN y la estructura importadora de la UE es sumamente reducida aunque hay un intercambio de algunos productos andinos con reducido valor agregado.

No se ha logrado desarrollar una oferta exportadora hacia la UE que incluya productos con mayor valor agregado.

En cuanto a las inversiones europeas en la Comunidad Andina (CAN), los flujos pese a ser menores en comparación con las realizadas en otras regiones, la Unión Europea (UE) ha sido el principal inversionista en los países de la subregión por encima de Estados Unidos.

En el Perú durante el fujimorismo se subastó más de 80 empresas del estado que provocó despidos masivos de empleados, se intentó encubrir con costosos programas de reconversión laboral, el mismo que debe ser investigado porque sus resultados fueron un gran fracaso y manejo oscuro de los fondos proveniente de endeudamiento externo.

El giro del comercio a partir de la reestructuración económica, es decir, las consecuencias de la transformación de una economía industrial basada en la producción de bienes de consumo, en una economía basada en la provisión de servicios y de información.

La migración interna y externa sólo favorece a las personas que posean educación, excluyendo a aquellos que carecen de ella y provocando más dificultades para cruzar el umbral de la pobreza.

La nueva realidad exige un intercambio de mayores oportunidades de reformas sustanciales en el campo de la educación para todos los niveles, incluyendo los estudios especializados, como forma de proteger a las comunidades de inmigrantes Latinos acosados por la nueva crisis que atraviesa Europa a partir de Grecia.

\section{Feudalismo y Neo-fundalismo}

En junio del 2010 se cumplió 41 años de uno de los desastres económicos más grandes de la historia del Perú: la Reforma Agraria de General Juan Velasco Alvarado.

Juan Velasco Alvarado, ocupó en 1969 los yacimientos y refinería de Talara para después terminar indemnizando vergonzosamente a los extranjeros. Promulgó la ley de Reforma Agraria y simultáneamente ocupó los grandes complejos agroindustriales azucareros llamados "Barones de la Azúcar", las industrias exportadoras florecientes; destruyó el boyante agro costeño que era una potencia en algodón. En los 6 años siguientes se expropiaron todas las haciendas del país, las tierras fueron adjudicadas a cooperativas agrarias de producción; alrededor de 2.9 millones de Hectáreas fueron adjudicadas a la

2 Académico y economista peruano, profesor de la PUCP. 
Sociedad Agrícola de Interés Social (SAIS), así como a las comunidades y otras organizaciones campesinas cerca de 3.5 millones de Hectáreas, que beneficiaron a 375 mil familias. Regionalmente fueron expropiadas y adjudicadas las tierras de uso agropecuario de la costa $53 \%$ y el de la sierra el $23 \%$.

Las cooperativas y las SAIS no resistieron el paso del tiempo, las primeras fueron divididas por los propios trabajadores en parcelas familiares y las tierras de la segunda fueron, salvo excepciones, distribuidas entre las comunidades campesinas.

$\mathrm{Su}$ esquema cooperativista acarreó un desastre productivo y generó cuevas de mafiosos en las azucareras; mató el algodón... en suma, muchos latifundios quedaron improductivos, donde aún el $80 \%$ tiene menos de cinco hectáreas, lo que los convierte en unos virtuales jardineros improductivos.

En resumidas cuentas, se puede decir, que la reforma agraria fue un fracaso económico pero, fue un éxito social. Desde el aspecto de la producción la reforma no fue exitosa, pero al redistribuirse las tierras, mejoraron los ingresos de centenares de miles de familias, es decir fue un fracaso económico pero un éxito social.

Desde el punto de vista social y político fue muy importante, puso fin al gamonalismo y a las relaciones serviles, democratizó la sociedad rural y permitió la conversión de los campesinos en ciudadanos.

En la actualidad, la política del gobierno apunta hacia la idea, que los campesinos y nativos no deben ser los propietarios de sus recursos, afirmando que éstos, no tienen los conocimientos necesarios y son pobres, motivo por el que esos recursos deben ser transferidos a los grandes inversionistas que tienen la tecnología y recursos económicos convirtiéndose de esta forma en sus "nuevos patrones".
Cuarenta y un año después de la Reforma Agraria del General Velazco hay neo-latifundistas mayores que antes de la reforma agraria, cabe citar el más grande de ellos el Grupo Gloria que controla alrededor de 60 mil hectáreas en la costa de Ancash y La Libertad, le sigue el grupo Romero con unas 20,000 Hectáreas en Piura, Huaral y San Martin, el grupo Dyer (Camposol) alrededor de 24 mil hectáreas en varios valles al grupo Maple 12 mil hectáreas en el valle del Chira, entre otros.

Existen decenas de neo latifundios que tienen más de mil hectáreas y las casi 150,000 hectáreas de nuevas tierras públicas que se ganarán en la costa con nuevas irrigaciones hechas con dinero público.

Hubiera sido interesante disponer de información que permitiera una comparación entre el stock de inversión extranjera y la inversión interna. Sin embargo, solo ha sido posible encontrar información del stock de la inversión extranjera, en los diferentes sectores de producción.

Cuadro No 7. Perú: Stock de Inversión Extranjera Directa. Millones de Dólares

\begin{tabular}{lcc}
\hline Sector & $2008(\mathrm{p})$ & Porcentaje \\
\hline Agricultura & 44.4 & 0.25 \\
Comercio & 720.4 & 4.01 \\
Comunicaciones & 3756.4 & 20.92 \\
Construcción & 161.4 & 0.90 \\
Energías & 2363.9 & 13.17 \\
Finanzas & 2721.3 & 15.16 \\
Industrias & 2828.2 & 15.75 \\
Minería & 3520.5 & 19.61 \\
Pesca & 163.0 & 0.91 \\
Petróleo & 355.9 & 1.98 \\
Servicios & 442.0 & 2.46 \\
Silvicultura & 1.2 & 0.01 \\
Transporte & 285.5 & 1.59 \\
Turismo & 63.5 & 0.35 \\
Vivienda & 525.8 & 2.93 \\
Total & 17953.4 & 100 \\
\hline (p)Actualizado a diciembre 2008 & \\
Fuente: Centro de Planeamiento Estratégico. Plan Perú \\
2021 ${ }^{3}$. & & \\
& &
\end{tabular}

3 CENPLAN. Plan Perú 2021. Plan Estratégico de Desarrollo Nacional. Pag. 81 
De esta información cabe destacar que las inversiones extranjeras en el sector primario representan el $22.76 \%$ de éstas, mientras que para el sector secundario el $32.75 \%$ y finalmente para el sector terciario el $44.49 \%$ de las inversiones extranjeras se encuentran en este sector, es decir, que los inversionistas extranjeros apuestan más en inversiones de comercio, comunicaciones, minería y servicios, y se inclinan menos por invertir en agricultura y pesca.

\section{CAUSAS DE LA POBREZA}

Un científico social que estudia y analiza la pobreza, la enmarca desde sus causas y ve su punto de partida. Alcock, 1997 señala que una vez que se ha reconocido que la pobreza existe, podemos identificar su causa esto podría darnos una base para desarrollar una política de cómo responder a este problema.

Según el autor existen dos grandes corrientes: las causas patológicas y las causas estructurales.

\section{Causas Patológicas}

Según Murray, 1990-1994, la pobreza es vista como el producto de una debilidad, ineficiencia o irresponsabilidad de los individuos y la respuesta de la política debe poner atención en el individuo, cambiando sus actitudes y comportamiento.

Las causas patológicas de la pobreza abarcan las siguientes categorías:

- El individuo: que abarca tres vertientes, la primera la indolencia e irresponsabilidad individual como causante de la pobreza

- La genética y relaciones del status social: se centra en la familia o comunidad, como también, en la heredada tal como, la inteligencia, parentesco, bajas aspira- ciones y el ambiente son internalizados como parte de los valores de los hijos en crecimiento, motivo por las que sus expectativas son bajas debido al medio en que se desarrollan, aceptando la pobreza como parte de su vida, porque nacen pobres y privados de lo elemental, por lo que los pobres se reproducen siendo ellos mismos quienes colectivamente a través de la cultura familiar y la comunidad donde viven, la que produce el conformismo $y$ un status quo.

- La psicología: que explica la falta de logros individuales por los rasgos de la personalidad adquiridos o desarrollados.

La desigual distribución de la riqueza, y el resultado de estilos de vida descuidados, por lo que las personas se dañan así mismos y a sus hijos, sea, por el consumo dañino como la basura o por no poder acudir a la salud preventiva. Siendo el estilo de vida subcultura, derivadas de las características personales en el nivel de educación que gobiernan ese comportamiento.

La concepción de causas patológicas tuvo su expresión en América Latina en la llamada cultura de la pobreza de Oscar Lewis 1967 según él, la existencia humana en un ambiente dado conlleva a un proceso de adaptación biológica y social que da pie a la elaboración de una estructura de normas, ideas y comportamientos desprendiéndose que los pobres son plenamente responsables por los acontecimientos desfavorables que les ocurren; carencia de educación y salud de los individuos que comparten esta concepción patológica de la causa de la pobreza, siendo necesario un cambio social y no sólo el comportamiento de los individuos, porque se ha podido comprobar que algunos que han estado en pobreza la han superado logrando salir al desarrollo personal $y / o$ familiar. 


\section{Causas Estructurales}

Según muchos estudiosos la corriente de la pobreza es un producto de las fuerzas sociales, los diversos eventos sociales producto de lo económico afectan a la población y crean la pobreza en los países desarrollados, la pobreza asociada a altos niveles de desempleo como resultado de las recesiones económicas internacionales y los bajos salarios, son otros de los componentes de la pobreza, los ocupados; el retiro de la fuerza laboral y pensiones bajas incrementan la pobreza de la población del adulto mayor; la presión para reducir el gasto público en beneficio de los desempleados o los empleados en situación de pobreza.

La pobreza es el resultado de operaciones de fuerzas sociales que interactúan en un orden económico y social. Creándose las circunstancias o condiciones que la población experimenta en la pobreza por ello es importante poner atención en las fuerzas estructurales con un modelo de causación social estructural.

Para Alcock la pobreza como todo fenómeno social es el producto del cambio social, y si queremos examinar la causa de la pobreza necesitamos examinar la dinámica del cambio social, entre los enfoque estructurales puede considerarse la pobreza en el marco de operación del sistema de producción capitalista: la propiedad de los medios de producción y la lógica de pauperización inherente al libre mercado de trabajo, en contextos de alta disponibilidad de mano de obra.

Una de las causas de la pobreza es porque la mayor parte de la población se separó de la tierra; perdiendo el control sobre los medios de producción, deviniendo en trabajadores asalariados pobres y explotados por el capitalismo, que también ha perdido la brújula

4 Dr. En Psicología Universidad de Cornell-USA de la ayuda al prójimo viendo en cada pobre el servil que trabaja sin dudas ni murmuraciones, siendo ellos los que aprovecharon de una coyuntura en la cual encontraron el cholo barato y explotado por su mismo cambio de estatus social y muchas veces ese salario no les alcanza para vivir en la capital, siendo la pobreza un producto directo del capitalismo por las ventajas que representaba.

\section{POBREZA vs INTELIGENCIA}

El Perú, es un país pobre, con altos índices de desnutrición y, sabemos que la inteligencia es un medio de desarrollo y progreso. Entonces, si los índices de pobreza son altos, implica que lo son también los de desnutrición y por ende, este aspecto, afecta directamente la inteligencia, en especial de los niños que son el futuro de la nación.

Pollitt', sostiene:

a) Los niños con desnutrición tienen antecedentes biológicos, sociales y familiares inusuales.

b) Las familias con niños desnutridos viven en condiciones de mucha pobreza y desorganización.

c) Los estados críticos de desnutrición pueden afectar significativamente el desarrollo del cerebro, si la desnutrición tiene lugar durante los periodos de crecimiento $y$ maduración cerebral.

d) En poblaciones donde la desnutrición es endémica, el contexto socio-económico de la desnutrición está constituido por múltiples variables (número de embarazos escasamente

La desnutrición como parte del conjunto de privaciones asociadas a la pobreza crónica, contribuye al riesgo pero no es un factor causal exclusivo o principal. 
La desnutrición es una de las muchas privaciones que caracterizan a la pobreza crónica y contribuyen al rezago en el desarrollo intelectual que sufren los menores. Sin embargo, como las privaciones son múltiples no se debe esperar que las intervenciones nutricionales en forma exclusiva sean suficientes para hacer una diferencia sustantiva en el desarrollo intelectual de esos menores. Es más, la continuidad de esas privaciones contribuirá a que los beneficios intelectuales logrados con los nutrimentos suplementarios desaparezcan.

\section{EXCLUSIÓN SOCIAL}

\section{Exclusión Social en el Perú}

Un estudio de Figueroa, Altamirano y Sulmont 1996 sobre exclusión social y desigualdad en el Perú cuyo origen es el Proyecto OIT y luego toma su curso propio. Para ellos el mercado de trabajo genera exclusión económica, debido a que no es capaz de absorber a toda la oferta de trabajo, en este sentido la desigualdad no es solo económica, al analizar la dimensión económica sistema productivo y mercados hay que medir también la dimensión política y el ejercicio de poder, deberes, derechos, ciudadanía y cultura, la desigualdad puede darse en una o más de estas dimensiones. La desigualdad no es sólo económica, producto y mercado, sino, que puede darse en otras dimensiones, tales como, la dimensión política en donde el ejercicio del poder es poderoso, el menoscabo de los derechos del ciudadano, la cultura.

Figueroa distingue dos tipos de mercados los walrasianos y lo no walrasianos.

\section{Mercados Walrasianos (León Walras equi- librio general y competencia perfecta)}

Compran y venden las cantidades que deseen al precio vigente, porque opera la competencia perfecta, resultado del equilibrio en el mercado de la cantidad ofrecida y la demanda, es decir, se rigen por los precios sean competitivos o no en un mercado perfectamente organizado desde el punto de vista de la competencia, cuanto mayor sean los activos y mayor la cantidad de bienes y servicios que el individuo pueda adquirir en los mercados no walrasianos, mayor será su ingreso real.

\section{Mercados no Walrasianos}

Se ajustan por cantidades o racionamiento cuantitativos, prevalece la competencia imperfecta e información imperfecta, no se compra o vende lo que se desea porque la incertidumbre y la información son imperfectas y los precios no son equilibrados, operan con exceso de oferta y/o demanda laboral, el crédito, el seguro, se ajustan al racionamiento.

Aquellos pobremente dotados de activos sociales y culturales serán más propensos a ser excluidos de los mercados no walrasianos, si el individuo es excluido del mercado laboral de crédito y de seguros su ingreso será menor y mas riesgoso, su capacidad de acumulación de activos económicos disminuirá.

En consecuencia, la desigualdad de ingresos y la distribución tiene mucho que ver con las dotaciones iniciales de los activos sociales y las políticas económicas del estado.

El funcionamiento del mercado de trabajo es fundamental para el proceso de exclusión por empleo asalariado, los salarios reales y las ganancias. Los excedentes pueden convertirse en desempleo o en empleo independiente, en esta lógica los ingresos de los trabajadores independientes son menores que los salarios, los excluidos se convierten en los más pobres de la sociedad.

A quienes se les excluye del mercado laboral? A los trabajadores con los más bajos 
activos culturales, ubicándolos muchas veces al final de la línea en el proceso de racionamiento, mercados de créditos y seguros, de aquí la importancia de la educación en la erradicación de la pobreza.

Lo que genera la desigualdad de ingresos en esta economía opera a través del mercado laboral, implica una cierta distribución del ingreso entre las ganancias los salarios y los ingresos de los trabajadores independientes, también se explica la exclusión de un segmento de la fuerza laboral del empleo asalariado.

En un mundo lleno de incertidumbre la desigualdad económica persiste e incluso se incrementa, debido a la naturaleza concentradora del intercambio en el mercado surgiendo que las personas con ingresos más altos ahorran más y acumulan más, embarcándose en proyectos más rentables y mas riesgosos porque tienen mayor capacidad de absorber riesgos; en cambio, los pobres están excluidos de los mercados básicos, esta desigualdad es más acentuada con el tiempo.

La pobreza es el resultado de un proceso social. La exclusión social de los mercados básicos es la causa de la pobreza, pero, la exclusión de otros mercados como los mercados de bienes de consumo es un efecto.

La exclusión social en cambio, es una categoría de análisis que ayuda a explicar los resultados, o sea, es uno de los mecanismos básicos a través del cual la variable exógena genera desigualdad social. La variable exógena comprende el conjunto de políticas del estado y las dotaciones iniciales de activos sociales de los individuos o familias.

En la teoría de la exclusión social tiene mucho que ver la historia, los parámetros, los sistemas, que se determinen a través del funcionamiento de los mercados del sistema político y de la ideología y valores sociales que se establecen culturalmente.
La exclusión social responde a una realidad social y una respuesta propiciada por Europa Occidental. Los estados Europeos buscan dar un trato mejor a los grupos de población afectados por las transformaciones y a las minorías, especialmente a los inmigrantes, la preocupación es si esto se puede trasladar y adaptar a los países en desarrollo, en los cuales la mayoría son pobres a los que no se les reconoce sus derechos sociales los mismos que no son cubiertos por el estado.

Según el estudio de Figueroa (1996) asume el enfoque de exclusión social en su vertiente de la muldimensionalidad de la pobreza, pues no reconoce que el problema no es un fenómeno exclusivamente económico, sino, que es un problema donde se superponen las dimensiones social, cultural y política.

El único problema de los pobres no es la escasez de recursos, sino, que son marginados por la sociedad y carecen de derechos reales o efectivos, debido a la desigualdad y exclusión son vistos como un proceso dinámico, en el cual las desigualdades iniciales heredadas desde la colonia se multiplican y profundizan a través del tiempo.

No se demuestra la existencia de salarios de eficiencia como fuente de exclusión social, en nuestro país los salarios de eficiencia funcionan para los profesionales y la mano de obra calificada, pero, la mano de obra no calificada sumada a la flexibilización laboral y la resistencia de las empresas a los aumentos salariales hacen improbable que se fijen salarios mayores a los equilibrios, y es una de las causas de la exclusión social.

La sobre oferta de la mano de obra sería la falta de acumulación de capital necesario para absorber a toda la mano de obra, el salario de equilibrio en el Perú es muy bajo.

Los trabajadores asalariados reciben sus ingresos y estos no le permiten salir de la po- 
breza, el salario mínimo legal del Perú se encuentra por debajo de la línea de pobreza, a esto hay que añadir a los pobres y excluidos que no perciben nada.

Se han ideados programas de compensación social distinguiéndose entres los nuevos o recientes pobres y los pobres antiguos o crónicos, convirtiéndose la pobreza en un círculo vicioso por lo que es necesario estudiar la condición permanente de pobreza desde un espectro más amplio sectorizando la población.

\section{Educación y Conocimiento: Factor Clave parA la erradicación de la Pobreza}

La educación está directamente relacionada con el capital humano, pues como hemos esquematizado anteriormente la educación forma parte de los conocimientos natos, ya sea ésta formal o informal.

La educación formal, la constituye aquella que recibimos en la escuela y que la universitaria o Institutos superiores, estas constituyen la base conceptual para cuantificar el capital humano.

También está la educación informal, constituida por las instrucciones que recibimos de la familia, el entorno y el auto aprendizaje.

Hay que comprender que estamos en una era científica, donde la tecnología ha derrotado al empirismo tradicional y la sociedad necesita cada día de más científicos. Esto ha modificado el nivel de todos los oficios aún de las profesiones. La tarea del hombre es cada día más exigente, su labor de inteligencia, su responsabilidad intelectual.

La universidad debe ampliar sus campos de investigación, cuanto más investigue asegurará la calidad de su trabajo creador, la universidad no debe despreocuparse de los derechos humanos, así como, de asegurar la formación de nuevas generaciones con profesores que den instrucción y no reducirlas a las tareas de una simple enseñanza y mínimo aprendizaje, el hombre por el hombre y para el servicio del hombre.

\section{Estafa Educativa}

En el Perú se convive con la estafa educativa que azota al país. Se pensó que en la primera década del siglo XXI había un renovado interés por la educación, tema que estuvo en orden del día en el Congreso planteándose soluciones de fondo, haciendo creer en un distinto porvenir para el sector educación; pero, como siempre, cuando los intereses personales o de un grupo prevalecen, se echa al tacho del olvido. Apareciendo los amigos de los negocios rápidos que abren escuelas y universidades descartables, con el afán de comercializar con las ilusiones de un pueblo navegando de fracaso en fracaso con programas parciales y medias verdades, para una mayor muestra el Ministerio de Educación, el mismo que actualmente, funciona en 6 distintos lugares y que para solucionar el problema se está construyendo otro edificio convirtiéndose en una tragedia educativa.

\section{ALTERNATIVAS PARA DISMINUIR LA POBREZA ESTUDIANTIL}

1ro.- Hoy en día se busca proteger el planeta y disminuir la contaminación ambiental, el reciclaje es una buena alternativa de negocio. Por qué no reciclar todo lo que se desecha en la universidad? para su posterior venta y obtener recursos que beneficien al estudiante. Los ingresos obtenidos irían directamente a los centros federados con un porcentaje por el trabajo efectuado.

2 do.- Crear un banco interno, cuyo monto mínimo para abrir una cuenta seria de $S$ /. 
10.00 , monto que se abonaría mensualmente y este fondo estaría inmovilizado por 6 meses. Estimamos conveniente que deben participar por lo menos 20,000 estudiantes, es decir, aproximadamente el 57\% de la población universitaria, lo que nos daría el monto de S/. 200,000 mensuales por seis meses nos da un S/. 1 200,000. Este fondo serviría para dar crédito estudiantil, préstamos blandos con un interés de $0.5 \%$. La idea es que los socios deberán seguir aportando S/. 10.00 mensuales para tener derecho a los beneficios, tales como, prestamos para investigación innovadora, para adquirir material educativo, para presentar proyectos empresariales entre otros.

La principal motivación de desarrollo no debe ser el dinero sino el deseo de superación. Debemos tener en cuenta que el servicio lidera la economía mundial y que el capital de riesgo debe estar al servicio de la producción.

\section{CAPITAL FÍSICO, HUMANO Y SOCIAL}

Si esquematizamos el capital físico, humano y social obtendríamos que el capital humano es un conjunto de capacidades productivas, resultado del conocimiento adquirido que puede este ser innato o nato.

Es importante generar capital humano, pues el nivel de producción será más eficiente, si los trabajadores tienen mayor grado de especialización.
Por consiguiente, podríamos afirmar que invertir en la educación de la sociedad, conlleva a la transformación de la misma, haciendo que las personas alcancemos una mejor calidad de vida, además que, educando a la sociedad se disminuirán algunas taras que nos impiden avanzar, tales como, la corrupción, los malos hábitos, e incluso una mejor elección de quienes nos gobiernen.

Sin una sociedad educada y saludable, no es posible alcanzar el desarrollo.

\section{Capital Social:}

Este capital son los valores convertidos en normas, tales como, la confianza, la solidaridad y la reciprocidad, que permiten la convivencia social.

Se puede establecer dos variantes del enfoque de capital social: Una utilizada y difundida por los organismos internacionales la misma que no se relaciona con la reducción de la pobreza, se presume que con un capital social más fuerte, los países o su mercado funcionan con mayor eficiencia o se ajustan mejor a las reformas estructurales. La otra variante más utilizada por los académicos pone énfasis en las redes de solidaridad como estrategia de supervivencia como antecedente el clásico trabajo de Larissa Lomnitz México 1975.

Así como, se contabiliza un capital físico $y$ un capital en dinero o financiero, habrá un capital natural un capital humano y un capital social.

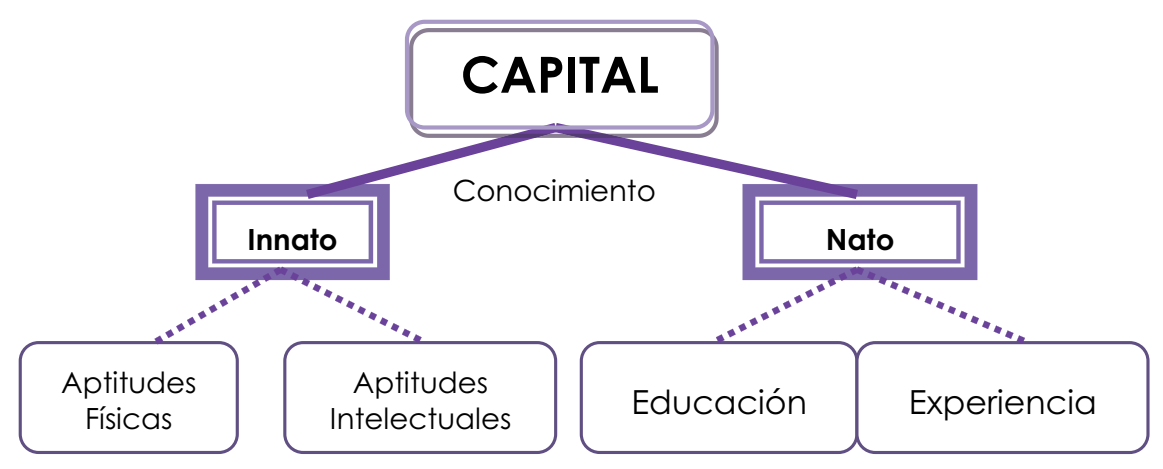


El capital puede ser visto como interacciones materializadas en redes, que forman parte de la estructura social, que tienen su propia trayectoria e historia y que, más allá de sus funciones configuran estructuras de oportunidades que tienen un impacto independiente sobre el sistema.

Por consiguiente capital social, se refiere a la capacidad de una comunidad en generar valor. Este capital explica las causas del desarrollo de un territorio, incide en las relaciones y es el capital que cuando más se produce más beneficios a largo plazo se obtiene, y como consecuencia mayor gobernabilidad democrática.

Este capital fomenta la acción colectiva, impulsa la responsabilidad social, acerca a las personas por medio de la confianza y el respeto, y es elemento esencial para el proceso de desarrollo de cualquier territorio.

En consecuencia el uso de la expresión capital social es hablar de Liderazgo y Empoderamiento o potenciación en términos ampliamente definidos, que abordaremos brevemente.

\section{Capital Humano}

Para abarcar el tema del capital humano en nuestro país, debemos iniciar afirmando que en nuestra sociedad existe un crecimiento desigual, limitado acceso a la tierra, al crédito, la educación y el empleo. Esto sumado al bajo presupuesto del PBI asignado a educación, impide el crecimiento de nuestro capital humano.

Un país puede crecer económicamente por disponer de mayor capital físico, así como, recursos naturales, e incrementar su tasa de crecimiento si se incrementa la productividad; sin embargo, para mayor productividad se requiere mayor tecnología y por ende mayor conocimiento y esto sólo depende de las habilidades y capacidades de los trabajadores, es decir, si se desarrolla el capital humano.

En Corea del Sur la prioridad de inversión es el capital humano, innovación y tecnología basado en la configuración de clúster que debe permitir un mayor acceso a mercados extranjeros, que busca romper el molde de país periferia.

El capital humano constituye la clave para el crecimiento sostenido del país, de aquí su importancia central en la elevación de la productividad, ya que ésta depende de la capacidad de incorporar progreso tecnológico y conocimiento, que a su vez depende de las habilidades y capacidades de los trabajadores. Así, la tasa de generación y absorción de tecnología y conocimiento de una economía depende críticamente del capital humano con que cuente.

En el caso del Perú, esto pone a la orden del día la imperiosa necesidad de poner en el centro de nuestra estrategia de crecimiento, la acumulación de capital humano, esto obviamente, supone un gran esfuerzo de inversión en educación, salud y lucha contra la pobreza.

\section{PBI y Gasto Público en Educación}

En los últimos años, en especial en el 2008, se han venido registrando ingresos per cápita altos en comparación a años anteriores. Así para el 2006 teníamos un PBI per cápita de 3.36 dólares, y en el 2008 se alcanzó el 7.6 dólares. Esto se explica por el incremento en la acumulación de capital en nuestro país, así como el incremento de los años de estudios alcanzados por la población en edad de trabajar.

Aunque, el PBI se ha venido incrementando con el paso de los años, y más aún en periodo 2006-2008, el gasto del PBI en edu- 
Cuadro No 15. Perú: Estructura de la PEA y PBI por Actividad Económica

\begin{tabular}{lrrrrrr}
\hline \multirow{2}{*}{ PBI por Actividad } & \multicolumn{2}{c}{$\mathbf{1 9 8 1}$} & \multicolumn{2}{c}{$\mathbf{1 9 9 3}$} & \multicolumn{2}{c}{$\mathbf{2 0 0 7}$} \\
\cline { 2 - 7 } Agricultura y pesca & PEA & \multicolumn{1}{c}{ PBI } & PEA & \multicolumn{1}{c}{ PBI } & PEA & PBI \\
Minería e hidrocarburos & 36.4 & 6.5 & 27.5 & 8.5 & 22.6 & 9.3 \\
Industria manufacturera & 1.8 & 5.6 & 1.0 & 4.4 & 1.3 & 6.5 \\
Electricidad, agua & 10.5 & 15.8 & 10.8 & 16.1 & 8.9 & 17.3 \\
Construcción & 0.3 & 2.0 & 0.3 & 1.9 & 0.2 & 2.3 \\
Comercio & 3.7 & 4.1 & 3.5 & 4.0 & 5.3 & 6.2 \\
Servicios & 12.0 & 15.0 & 17.7 & 14.5 & 17.8 & 16.2 \\
Total & 35.3 & 51.0 & 39.2 & 50.6 & 44.0 & 42.4 \\
\hline
\end{tabular}

Fuente: Centro de Planeamiento Estratégico. Plan Perú $2021^{5}$.

cación no ha variado significativamente. Reflejando el poco interés del estado por este sector importante para el incremento del capital humano en nuestra nación.

Observamos que el sector productivo terciario, es decir comercio y servicios, es el sector que aporta significativamente al PBI y es en el que se distribuye la mayor PEA.

La tasa de crecimiento del Producto Bruto Interno (PBI), se ha convertido en el criterio fundamental de autoevaluación del desempeño en el actual gobierno, y como elemento de juicio para validar el modelo económico.

El PBI, es un indicador relevante y útil para medir el nivel de actividad económica y establecer comparaciones entre diferentes economías y a través del tiempo; omite, sin embargo, la distinción entre los ingresos generados por residentes y no residentes en el país; no es un reflejo de calidad de vida; elude los problemas distributivos y tiene una perspectiva exclusiva en el corto plazo; hay otros referentes, tales como, los Indicadores de Desarrollo Humano (IDH) y el de Productos Interno Neto Ecológico (PINE).
El Producto Bruto Interno (PBI) ha tenido altos picos en el Perú. Estabilizar la tendencia de crecimiento, ello se traduce en desarrollo, equidad, inclusión y paz. Capacidad de creación de riqueza entre la mayoría de la población, el Estado juega un papel de promotor y el sector privado brinda el mejor de los ejemplos con los importantes programas de responsabilidad social logrando que surjan los distintos sectores.

El PBI mide el nivel de actividad económica para un espacio geográfico determinado a diferencia del producto nacional bruto (PNB) que lo establece para los residentes del país.

El PNB deduce del PBI las utilidades de las empresas transnacionales propiedad de extranjeros menos las remesas recibidas del exterior. En el 2008 US\$ 8346 y 2009 USA 7064 millones en el primer trimestre ascendieron a US\$2,258 millones, equivalente a casi el 6\% del PBI.

Este es un agregado a la contabilidad nacional que suma los ingresos por remuneraciones de los independientes de la ciudad y del campo y de los preceptores de utilidades

5 CENPLAN. Plan Perú 2021. Plan Estratégico de Desarrollo Nacional. Pag. 76 
de empresa, rentas, alquileres, intereses netos y otras cuentas no se puede diferenciar; quienes son los mayores o menores beneficiarios en tiempos de crecimiento o crisis desde que el INEI elabora este cómputo no se puede distinguir entre los ingresos de los independientes y las utilidades de las empresas, pues, todo se coloca en el excedente de explotación.

Una mayor diferencia entre las tasas de interés activas y pasivas es una contribución contable directa al PBI, pero negativa para el aparato productivo.

Diversas empresas están anunciando la ampliación de su capacidad productiva y con ello la creación de nuevos puestos de trabajo. En Trujillo, Chiclayo y Piura se desarrollan nuevas urbanizaciones. El norte tiene un potencial turístico muy apreciado por las playas de Máncora, Punta Sal, Cabo Blanco, Colán, Pimentel y Huanchaco en las que se tiene un gran margen para aprovechar el turismo: por la pesca deportiva de altura, la tabla hawaiana o simplemente a descansar, variedad de arte popular y la cocina regional norteña, aun más, se tiene inmensos tesoros arqueológicos, tales como, Chan Chan, museos de primera talla como el Señor de Sipan y el recientemente inaugurado Huacas de Moche, imponentes casonas y templos virreinales, recursos termales como Cachicadán en la sierra liberteña y otros. La Libertad, Lambayeque y Piura donde la iniciativa privada ha sido importante por consolidación de la agroindustria, la inversión sostenida en pesca, minería, manufactura y últimamente en construcción.

Si bien es cierto, hay problemas de seguridad, esto depende del Ministerio del Interior, Presidentes regionales y alcaldes, quienes deben trabajar en salvaguarda de la seguridad ciudadana y turística.

\section{CONTRIBUCIÓN DEL CONTADOR PÚBLICO EN EL DESARROLLO Y CRECIMIENTO ECONÓMICO}

Es necesario que los Contadores Públicos se pongan la camiseta de la Responsabilidad social que le compete manifestando su valor, su ética en lo que hace, la importancia de preservar la integración de todos los estados, su mirada debe retrotraerse en la Historia, recordando el pasado y de allí ir escalando para llegar al presente, desechando lo que no estuvo correcto en el pasado, aprovechando y superando lo que estuvo bien con el fin de lograr el éxito, no solo empresarial sino también de la clase trabajadora.

\section{RESPONSABILIDAD SOCIAL DEL CONTADOR PÚBLICO ANTE LA PO- BREZA}

La responsabilidad es mucho más de lo que nos da la realidad, es llevar a efecto las exigencias, los tópicos, es rendir cuenta, no sólo a nivel empresarial, sino además social.

Dar fruto con nuestro trabajo en beneficio de la sociedad de la comunidad, ser íntegros, rectos, probos y honestos. Realizar todo trabajo con mentalidad independiente, es parte fundamental de la responsabilidad social del contador público. Todo contador debe ser confidencial, es parte importante de la vida profesional.

Como profesionales críticos y analistas debemos observar las disposiciones normativas siempre, estemos de acuerdo o no. Debemos permanentemente actualizarnos, colaborar con todos los entes de gobierno, ser respetuoso del colega, con ellos como personas y como conducta ética, nuestras acciones deben enmarcarse dentro de la ética profesional. Ser ético en lo personal, y necesariamente ético en el desempeño de la profesión. 
El contador tiene una responsabilidad con la sociedad y el estado. Una empresa no se quiebra de la noche a la mañana, y el contador lo sabe, es consciente de ello.

Por las continuas denuncias y avisos periodísticos por reporteros honestos y responsables, tenemos conocimiento que el Estado está entregando por partes nuestro país a las empresas foráneas, desligándose de su gran responsabilidad.

Reflexiones:

- Las comunicaciones hoy en día son de capital privado, foráneo.

- La salud igualmente está en el sector privado, la mayor parte.

- Las pensiones de quienes han entregado su vida de labor, inducidos por el estado, se encuentran en empresas del sector privado.

- La electricidad, así como otros servicios hoy en día son de capital privado.

Las experiencias multinacionales son tan antiguas, que su avance permitirá que se entiendan entre ellas, desligándose del estado y éste a su vez del rol que asume con el país, mediante los que lo dirigen, cada uno a su turno.

Las utilidades o beneficios de las empresas privadas, publicas, asociaciones y otros son de carácter social.

Mando asimétrico, en lo social la globalización y de quienes tienen manejo del capital, en pocas manos, lo que repercute en aumento de la pobreza, que es cada vez más evidente.

Trataremos la competencia del Contador Público y su Responsabilidad social frente a la pobreza y la exclusión social, que debe trasmitir la esencia de sus conocimientos basada en la historia, que es el pasado frente al futuro que es la información virtual y que, al hablar de pobreza debe sumergirse en estas dos comparaciones, no eludiendo su responsabilidad que le compete desde antaño y para ello debemos trasladarnos a la historia, que refleja como hemos ido superando escollos hasta nuestros días.

El Contador además de generar información de y para la empresa, es un ser con conocimiento y capacidad de análisis que puede y debe aportar ideas con propuestas que ayuden al mejor funcionamiento de la comunidad en general, aquí ya estamos refiriéndonos a la responsabilidad social del contador.

La sociedad deposita su confianza en los Contadores, ya que éstos dan fe del buen manejo dentro de la empresa, teniendo presente que las empresas pagan impuestos, los que finalmente deben ser utilizados en beneficio de la sociedad. El Contador dentro de una empresa cumple, y debe cumplir una función interventora, ya que puede validar y aplicar procesos que la empresa pone en marcha, velar por que estos procesos refuercen la conservación del ambiente y a la vez el bienestar de la comunidad por medio de acuerdos sociales.

Jack Araujo ${ }^{6}$ menciona a este respecto que la contabilidad social esta "referido a hechos sociales tanto del recurso humano en la empresa como de las que suceden fuera de ellas en la comunidad en la que está inserta”. Pues en estos tiempos, ya es una necesidad que el Contador tome decisiones en relación a su participación en la gestión social.

Aquí cabe citar a Adela Cortina": "reflexionar sobre lo ético de la sociedad civil equivale a conversar, a iniciar una conversación, para tratar de construir un proyecto de sociedad que nos tenga en cuenta a todos,

6 Araujo Jack Alberto. Contabilidad social. Página 35. tiempos gráficos ediciones. Medellín, Colombia, 1999.

7 Cortina Adela. Democracia participativa y sociedad civil. Una ética empresarial. Siglo del hombre editores. Página 70-72. Bogotá, 1998. 
que no margine a nadie, que no posibilite la exclusión y que incluya la verdad a todos los miembros de la sociedad"

Si comparamos el principio rector de la contabilidad: Debe $=$ Haber con la frase citada por Adela Cortina, observamos que este enfoque no admite ningún tipo de exclusión, donde ese "debe" y la posesión son una expresión de inclusión verdadera a todos los miembros de la sociedad, sin marginación alguna.

En esta relación, el Contador asume no sólo una responsabilidad ética, sino también social, pues Debe $=$ Haber, expresa la igualdad del tú a tú, obliga al Contador a dar una mirada más analítica a la sociedad, con miras a construir un futuro mejor con libertad y responsabilidad. La responsabilidad es un hecho que provoca obras productivas, es la relación de igualdad que implica la responsabilidad social del Contador.

De otra parte, la " $\mathrm{T}$ ” esquemática contable, no sólo debería representar un símbolo contable para el profesional en Contabilidad, sino, además debe ver en ella la simbología del equilibrio.

La Responsabilidad Social del contador va más allá de obras sociales, la reflexión crítica, la normatividad, su responsabilidad es una apuesta por el desarrollo del conocimiento contable a través de las más sentidas necesidades de la sociedad en general. De allí que la relación de equilibrio Debe=Haber, propicia acuerdos en las diferencias, logrando la armonía.

El Contador debe brindar apoyo en el servicio al pueblo, conciliar diferencias entre empresa-comunidad, tolerancia y respeto hacia otras culturas, actuar bajo la lógica de una estructura adecuada según las necesidades de su entorno, e incorporando conocimiento común, ya que el Contador debe actuar socialmente propiciando el equilibrio, la justicia y la igualdad.
Tengamos presente que la contabilidad presenta una contribución al sistema económico, éste juega un papel fundamental si de consolidar la brecha entre pobres y ricos se trata. El Contador debe despertar una reflexión crítica, dejar de lado la lógica del desarrollo del capitalismo que sólo busca mantener o generar más pobreza y miseria y por ende exclusión.

El Contador de hoy, tiene por reto el forjarse una actitud crítica y reflexiva ante las prácticas económicas, contables y administrativas, tengamos presente que el Contador es el fedatario de las buenas prácticas dentro de una empresa. Requiere una participación activa en la transformación y construcción de la realidad económica-social, en busca del bienestar, igualdad y equilibrio social. Su postura dentro de sus análisis debe apuntalar a la construcción de respuestas a las necesidades sociales.

El Contador y el Sistema Nacional de contabilidad tienen la función social de contribuir y propiciar la formación de un Estado donde la contribución al bien común sea adecuada y significativa. El apoyo del Contador al respecto es imprescindible, en la rendición de cuentas, ya que éste es el pilar básico de la transparencia, dicha información permite tomar conciencia de lo hecho y lo por hacer, principio de la responsabilidad social.

\section{CONTRIBUCIÓN DE LOS CONTA- DORES EN LA ERRADICACIÓN DE LA POBREZA}

Si bien es cierto Perú, incrementa sus índices de crecimiento económico, sin embargo, ello no garantiza la reducción de la pobreza. Para alcanzar un crecimiento de calidad y que tenga alcance social es necesaria una redistribución directa desde el Estado, teniendo en cuenta variables no únicamente 
económicas y políticas, sino también las contables.

En el campo de la contabilidad, se ha estimado que para erradicar la pobreza en el Perú, se requiere un subsidio anual del $4.7 \%$ del PBI y para erradicar la pobreza extrema uno del $0.7 \%$ del $\mathrm{PBI}^{8}$.

Cabe resaltar que el crecimiento económico en nuestro país se debe en gran medida a las exportaciones mayormente en el sector primario-extractivo; los que se desarrollan lejos de los centros urbanos, aunque estas empresas tienen a ser intensivas en capital, no generan empleo suficiente ya que concentra solamente el $2 \%$ de la población económicamente activa (PEA).

Por otro lado, siendo Perú, un país centralista, sabemos que la gran cantidad de MYPES se establecen en la capital, si bien es cierto, el Estado da un tratamiento especial a este tipo de empresa, la productividad de éstas suele ser escasa y sus bienes y servicios están dirigidos a sectores con ingresos menores y son éstas empresas las que absorben, a pesar de su escaso capital, la mayor cantidad de mano de obra, convirtiéndose en una importante fuente de empleo y subempleo.

El crecimiento económico no debe ser sólo sectorial sino también social. Detrás de las gestiones empresariales se encuentra un grupo social encargado de hacerla funcionar. Es necesario que la buena distribución se dé desde todo nivel, es decir, si una empresa aumenta su productividad aumente también el salario a sus trabajadores.

Esta afirmación respondería a la incógnita... Por qué si la economía de un país crece aceleradamente, mayor es la desigualdad? Simplemente porque el crecimiento no tiene efecto distributivo primario.
El índice Gini, es uno de los principales indicadores de la distribución de los ingresos. Cuanto más cerca sea este valor a 1 , significa que peor es la distribución del ingreso, en tanto cuanto más cercano sea este valor a 0 , indicaría que la distribución de los ingresos es más equitativa. El coeficiente Gini sólo recoge sueldos y salarios y deja de lado los ingresos por capital (ganancias interés y rentas de las personas).

Observamos que en periodo 2004 al 2008, la variación en el índice Gini no ha sido notable, así tenemos que en el 2008 se registra el menor valor, 0.479 ; mientras que el mayor se registró en el año 2005 con un valor de 0.508 .

Cuadro No 17. Índice Gini: Evolución de la desigualdad de Ingresos en el Perú 20042008

\begin{tabular}{lccccc}
\hline \multicolumn{1}{c}{$\begin{array}{c}\text { Ámbitos } \\
\text { geográficos }\end{array}$} & $\mathbf{2 0 0 4}$ & $\mathbf{2 0 0 5}$ & $\mathbf{2 0 0 6}$ & $\mathbf{2 0 0 7}$ & $\mathbf{2 0 0 8}$ \\
\hline Global & $\mathbf{0 . 4 9 2}$ & $\mathbf{0 . 5 0 8}$ & $\mathbf{0 . 4 9 9}$ & $\mathbf{0 . 5 0 7}$ & $\mathbf{0 . 4 7 9}$ \\
Urbana & 0.448 & 0.473 & 0.454 & 0.455 & 0.431 \\
Rural & 0.404 & 0.410 & 0.411 & 0.432 & 0.425 \\
Dominios & & & & & \\
$\begin{array}{l}\text { Lima Metro- } \\
\text { politana }\end{array}$ & 0.442 & 0.497 & 0.460 & 0.452 & 0.426 \\
Resto urbano & 0.423 & 0.428 & 0.421 & 0.439 & 0.419 \\
Rural & 0.404 & 0.410 & 0.411 & 0.432 & 0.425 \\
Regiones & & & & & \\
Costa urbana & 0.405 & 0.396 & 0.393 & 0.422 & 0.384 \\
Costa rural & 0.395 & 0.357 & 0.370 & 0.388 & 0.376 \\
Sierra urbana & 0.444 & 0.465 & 0.444 & 0.452 & 0.458 \\
Sierra rural & 0.394 & 0.416 & 0.401 & 0.421 & 0.415 \\
Selva urbana & 0.401 & 0.414 & 0.428 & 0.447 & 0.425 \\
Selva rural & 0.365 & 0.365 & 0.400 & 0.423 & 0.418 \\
Lima metro- \\
politana
\end{tabular}

Fuente: Centro de Planeamiento Estratégico. Plan Perú $2021^{9}$.

\footnotetext{
8 http://www.rel-uita.org/old/internacional/hambre/pobreza.htm. Información proporcionada al 2003.

9 CENPLAN. Plan Perú 2021. Plan Estratégico de Desarrollo Nacional. Pag.36
} 


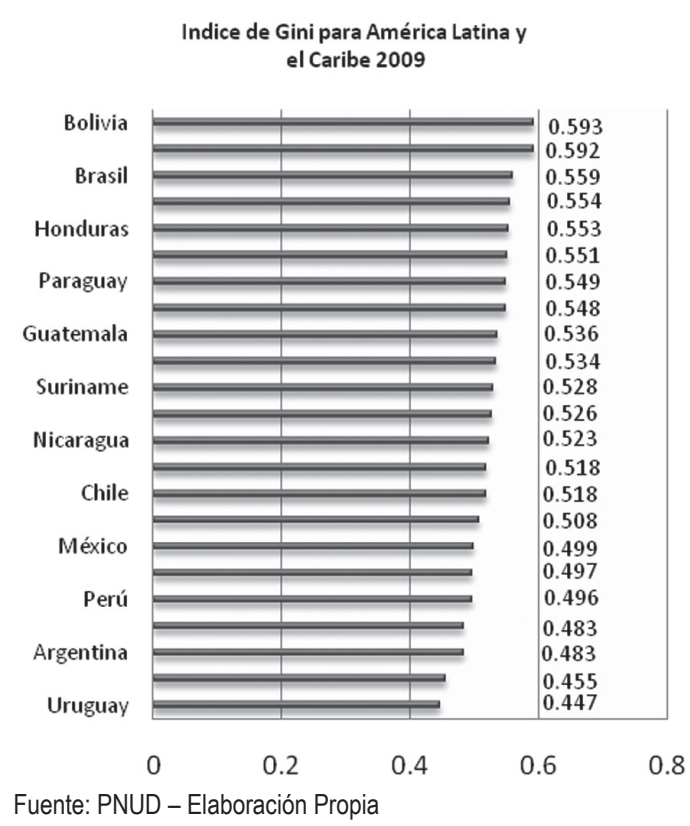

En una visión general a América Latina y el Caribe, Perú, para el año 2009, se encuentra entre los 5 países con menor índice de Gini, es decir entre los cinco países con mejor distribución de ingresos, sin embargo, los países con la mejor distribución de ingresos en el mundo son Holanda, Dinamarca, Eslovaquia, Países Nórdicos, Australia y Japón, estos países tienen indicadores de Gini por debajo de 0.25 , es decir, que nuestro país tiene todavía mucho que mejorar.

\section{ÉTICA Y RESPONSABILIDAD SOCIAL DEL CONTADOR}

Como ser esencia e historia, frente a las transformaciones del mundo empresarial?

El Contador a través de sus conocimientos debe tener presente la responsabilidad social en su actuar y su intervención con su entorno en espacio y tiempo, los límites que le rodean, frente a la población, en sus diferentes complejidades, ya no sólo identificándose con el dueño del negocio sino con el personal que labora en el mismo y el pueblo que debería estar pendiente de su desarrollo profesional, por lo que en los diferentes campos que le toca desarrollarse profesionalmente debe reflexionar sobre la cultura, costumbres y su campo de acción, así tenemos, que de nuestra acción contable logremos la comprensión de todos nuestros entornos.

A través de la historia el profesional era conocido como los quipukamayocs el que mediante los quipus que eran los registros en los que el inca ordenaba el control del registro de su gestión, el contador de ese entonces utilizaba la yupana como medio de cálculo, luego llegaron las máquinas de escribir y sumar luego estamos en la época de la gran revolución que son las computadoras y los medios virtuales, aquí el contador tuvo que aplicar su juicio y visión integral de su responsabilidad social, no sólo pensando en el empresario sino en los trabajadores y luego el pueblo que le rodea, aplicando la parte humana en todo el entorno como medio de vida del contexto social, la historia la aplicamos para criticarla y mejorarla, para entenderla tenemos que partir desde su inicio, es decir, el nacimiento de la profesión y como poco a poco hemos dejado de participar como principales actores con proyección.

Frente a esto tenemos varios escritores, de los muchos elegimos a Max Weber en su libro "la ética protestante y el espíritu del capitalismo" en el que escribe "el único modo de agradar verdaderamente a Dios es el cumplimiento en el mundo de los propios deberes profesionales, por ello el profesional se entrega en alma y cuerpo a realizar su vocación", aquí podemos apreciar, la misión de cumplir de todo buen profesional con la ética que se enmarca muchas veces en la vocación de servicio.

Nuestra conciencia obliga a cumplir con un deber moral, por lo que el ser autónomos, nos está vedado a todo buen profesional, a huir de las generaciones abusivas sobre sociedades concretas, a los sacerdotes que ven 
el alma, a los médicos que cuidan nuestro cuerpo y los juristas que cuidan la cosa pública, todos ellos pronuncian un juramento al ingresar a ejercer su actividad con reglas de valores morales.

Todo profesional se enmarca en el deber moral, en el ejercicio de su profesión con conciencia y autonomía, la modernidad nos orienta a la parte económica convirtiéndola en ética autónoma, en la empresa realizamos acciones voluntarias que emprende la empresa para llegar a donde el estado no puede, en un acto reflexivo de la persona, la responsabilidad social del contador es mirar con reflexión crítica los actos, en condiciones históricas y culturales.

\section{CONCLUSIONES}

- La solución a la pobreza y pobreza extrema debe ser enfrentada por la Universidad, Estado, Y LA sociedad civil y/o privada.

- Estimamos como fundamental la participación del Contador Público más humanizado con la realidad y la necesidad de adaptarse a los cambios, los cuales deben reflejar la realidad concreta, no limitándose a los cálculos de números fríos, de la empresa y su proyección al futuro, pero de la mano con sus trabajadores y el país.

- La realidad afecta a la gran mayoría de las culturas y organizaciones, cada vez el empresario es más exigente, pero esa exigencia debe ir de la mano del cuidado del medio ambiente y de los sueldos y/o salarios que se fijan dentro de una empresa y su aporte social con los trabajadores debe hacer frente a los problemas humanos de sus colaboradores que con su esfuerzo, entrega y desarrollo dentro de la empresa coadyuvan al éxito empresarial.
- El Contador Público debe retomar su liderazgo, que lo ha dejado por comodidad del facilismo, olvidándose de su entorno, dejando a la merced de informes fríos los resultados de la empresa, olvidándose que es corresponsable de la pobreza y exclusión social, que debe erradicarse y lograr que surja el desarrollo, no sólo empresarial sino también el de los trabajadores que con su esfuerzo y entrega logran que la empresa resulte exitosa, trabajadores que con sus buenos ingresos lograrán que sus familias salgan adelante en estudio, salud, bienestar que redundará en el éxito del país.

- Crear mecanismos de consulta ciudadana adecuados, de modo que el pueblo pueda resolver si acepta o no la concesión de los bienes que podrían afectar su entorno socio-ambiental, obviamente antes que el Estado determine dar las concesiones.

- Para erradicar la pobreza se requiere que hombres y mujeres sean capaces de tomar sus propias decisiones. El estado debe asegurar que las personas puedan incrementar sus capacidades y sus activos, además de asegurar un ambiente propicio, apoyando alianzas políticas y de mercado, en beneficio de los más pobres.

- La Inversión social, genera capital humano, la que se transforma en productividad, progreso tecnológico y competitividad.

- Maquila es un modelo que busca el uso de tecnología con una fuerza laboral oprimida. Las maquiladoras sacrifican ingresos fiscales para el gobierno del país huésped. La maquilación, se da en zonas donde las empresas se pueden establecer pagando un costo mínimo de impuestos y donde la explotación de niños y mujeres es muy alta, si es que nuestros compatriotas se dejan los salarios son de hambre a ella pertenecen pequeñas empresas locales, 
las cuales son subcontratadas por corporaciones multinacionales.

- Debemos ver los efectos perniciosos sobre la economía real de una actividad financiera mal utilizada. Los flujos migratorios no realizados adecuadamente. La explotación sin reglas de los recursos de la tierra. Aumento exagerado de las desigualdades. Aumento de la desigualdad entre grupos sociales dentro del país. Tipo de subdesarrollo derrochador y consumista, frente a situaciones persistentes de miseria y deshumanización.

\section{REFERENCIAS BIBLIOGRÁFICAS}

- ANELOU YPEIJ.- Produciendo contra la pobreza.-Instituto de Estudios Peruanos (IEP) 1ra edición 2006.
- ARAUJO, JACK ALBERTO. Contabilidad Social. Tiempos Gráficos Ediciones. Colombia, 1999.

- ARRANZ, M: FREIRE M. y GUISAN. An International Comparison of Education, Growth and Employment. Investigación Económica, Vol 235. UNMSM, Mexico, 2001.

- BRAYAN MAGREE- Historia de la Filosofía.- Editorial fondo de la cultura económica. Mexico 2001.

- BENDISKI, I., GORDINEZ, V. MENDOZA, M. La industria maquiladora. Revista Trayectoria. Año 4, No 7. 2002.

- CEPLAN: Centro de Planeamiento Estratégico. Plan Perú 2021, Plan Estratégico de Desarrollo Nacional. Perú, 2010. 